\title{
PENGARUH UKURAN PARTIKEL BIOCHAR BAMBU TERHADAP SIFAT FISIKA TANAH, KADAR HARA N, P, K DAN PRODUKSI TANAMAN KEDELAI (Glycine max L.) SELAMA DUA MUSIM TANAM (JAGUNG - KEDELAI) \\ (Influence of Different Sizes of Bamboo Biochar on Soil Physical Properties, Nutrient Uptace N, P, K and Soybean Crop Yield During Two Growing Season (Corn -Soybean))
}

\author{
Putri Fadilah', Manfarizah', Darusman ${ }^{1 *}$ \\ ${ }^{1}$ Program Studi Ilmu Tanah, Fakultas Pertanian, Universitas Syiah Kuala \\ *Corresponding author: Darusman@unsyiah.ac.id
}

\begin{abstract}
Abstrak. Bambu merupakan salah satu bahan baku yang dapat digunakan untuk memproduksi arang aktif karena mempunyai daya adsorbsi dan kapasitas tukar kation yang tinggi. Biochar dengan ukuran partikel yang berbeda memberikan pengaruh yang berbeda terhadap tanah. Penelitian ini menggunakan rancangan acak kelompok (RAK) non faktorial dengan empat perlakuan ukuran partikel biochar yang diulang sebanyak tiga kali sehingga menghasilkan 12 satuan plot percobaan dengan dosis biochar sebanyak 15 ton ha ${ }^{-1}$. Perlakuannya yaitu $\mathrm{P}_{0}$ : Kontrol, $\mathrm{P}_{1}$ : Biochar berukuran 5.00 - $2.00 \mathrm{~mm}, \mathrm{P}_{2}$ : Biochar berukuran $2.00-1.00 \mathrm{~mm}, \mathrm{P}_{3}$ : Biochar berukuran $1.00-0.5 \mathrm{~mm}$.Tiga parameter yang diteliti dalam penelitian ini yaitu parameter sifat fisika tanah meliputi Berat volume tanah, Porositas, Permeabilitas, Kapasitas menyimpan air (WHC), Daya hantar listrik (DHL), dan pH tanah $\left(\mathrm{H}_{2} \mathrm{O}\right)$; parameter kadar hara tanah meliputi N-total, P-total, dan K-total; dan parameter produksi meliputi polong berisi, polong hampa, total polong, berat biji kering, berat 100 biji dan produksi tanaman kedelai ton ha ${ }^{-1}$. Penelitian ini dilaksanakan pada kebun percobaan ACIAR Fakultas Pertanian Universitas Syiah Kuala sejak bulan Juli sampai November 2020, analisis tanah dan kadar hara dilaksanakan di Laboratorium Fisika Tanah dan Laboratorium Penelitian Tanah dan Tanaman, Fakultas Pertanian Universitas Syiah Kuala. Hasil penelitian ini didapatkan bahwa kadar hara $\mathrm{N}$-total dan berat 100 biji berpengaruh sangat nyata pada taraf $1 \%$. Ukuran biochar bambu yang baik secara keseluruhan dalam memperbaiki sifat fisika tanah, kadar hara tanaman, dan produksi tanaman kedelai adalah biochar yang berukuran $1.00-0.5 \mathrm{~mm}(\mathrm{P} 3)$.
\end{abstract}

Kata Kunci: Biochar Bambu, Sifat Fisika, Produksi Kedelai

\begin{abstract}
Bamboo is one of the raw materials that can be used to produce activated biochar because it has high adsorption and cation exchange capacity. Biochar with different particle sizes has different effects on the soil. This study used a non-factorial randomized block design (RBD) with four treatments of biochar size which were repeated three times so as to produce 12 experimental plot units with a biochar dose of 15 tons ha ${ }^{-1}$. the treatments were $\mathrm{P}_{0}$ : Control, $\mathrm{P}_{1}$ : Biochar measuring $5.00-2.00 \mathrm{~mm}, \mathrm{P}_{2}$ : Biochar measuring $2.00-1.00 \mathrm{~mm}, \mathrm{P}_{3}$ : Biochar measuring $1.00-0.5 \mathrm{~mm}$. Three parameters studied in this study were of soil physical properties including Bulk density, Porosity, Permeability, Water holding capacity (WHC), Electrical conductivity (DHL), and soil $\mathrm{pH}\left(\mathrm{H}_{2} \mathrm{O}\right)$; soil nutrient content parameters include N-total, P-total, and $\mathrm{K}$-total; and production parameters include filled pods, empty pods, total pods, dry seed weight, weight of 100 seeds and soybean crop production ton ha- ${ }^{-}$. This research was carried out at the ACIAR experimental garden, Faculty of Agriculture, Syiah Kuala University from July to November 2020, soil analysis and nutrient content were carried at the Soil Physics Laboratory and Soil and Plant Research Laboratory, Faculty of Agriculture, Syiah Kuala University. The results of this study showed that the total $\mathrm{N}$-nutrient content and weight of 100 seeds had a very significant effect at the $1 \%$ level. The overall good size of bamboo biochar in improving soil physical properties, plant nutrient content, and soybean production is biochar measuring $1.00-0.5 \mathrm{~mm}\left(\mathrm{P}_{3}\right)$.
\end{abstract}

Keywords: Bamboo Biochar, Physical Properties, Soybean Production

\section{PENDAHULUAN}

Rendahnya produktivitas lahan pertanian di Indonesia disebabkan oleh beberapa faktor, salah satunya yaitu faktor manusia yang belum menerapkan sistem pengelolaan lahan yang tepat dan berkelanjutan sehingga terjadi degradasi atau penurunan kualitas lahan. Penambahan 
pembenah tanah seperti bahan organik (serasah, kotoran ternak), dolomit, dan biochar ke dalam media tanam banyak ditempuh oleh petani. Biochar dapat menjadi bahan pembenah tanah karena kemampuannya dalam mengurangi terjadinya run off dan mampu menyediakan unsur hara bagi tanaman (Haryadi, 2016). Menurut Tang et al. (2013) mengungkapkan bahwa biochar dapat bertahan lama di dalam tanah atau relatif resisten terhadap serangan mikroorganisme, sehingga proses dekomposisi berjalan lambat.

Biochar merupakan hasil dari proses pembakaran bahan organik atau biomassa mentah pada kondisi tanpa atau sedikit oksigen (pyrolysis) dengan temperatur $250-500^{\circ} \mathrm{C}$ dalam bentuk bahan padatan kaya karbon (Lehmann, 2007). Biochar berbeda dengan bahan organik lainnya karena biochar yang sudah dicampur dengan tanah dapat bertahan lama di dalam tanah hingga ribuan tahun dan mampu mensekuestrasi karbon dalam tanah. Sumber biochar, jenis biochar dan jumlah bahan baku biochar yang digunakan berpengaruh terhadap kualitas tanah dan hasil tanaman yang dibudidayakan. Bambu merupakan salah satu bahan baku yang dapat digunakan untuk memproduksi biochar karena mempunyai daya adsorbsi dan kapasitas tukar kation yang tinggi. Komponen kimia bambu berperan pada proses pembuatan biochar berkualitas tinggi seperti kadar selulosa, lignin dan hemiselulosa (Nurhayati, 2000).

Selain itu, bambu memiliki keuntungan lain seperti mudah didapatkan, pertumbuhannya cepat dan memiliki kadar abu rendah. Biochar yang terbuat dari bambu memiliki daya adsorpsi lebih tinggi dibandingkan dengan biochar yang terbuat dari kayu tradisional (Hua, 2009). Silika yang tersisa pada batang bambu yang telah mengalami pyrolisis dapat mempengaruhi adsorpsi. Biochar bambu mengandung karbon sebanyak $82,1 \%$, jumlah tersebut dapat memaksimalkan kebutuhan karbon dan dapat digunakan sebagai sumber energi untuk adsorpsi polutan tanah (Lee et al., 2013).

Dalam mengaplikasikan biochar, perbedaan bahan baku biochar dan ukuran partikel biochar dapat memberikan pengaruh yang berbeda pada tanah (Shenbagavalli dan Mahimairaja, 2012). Menurut Santi dan Goenadi (2010), ukuran partikel biochar berpengaruh terhadap kepadatan tanah melalui sebaran partikel tanah dan pengisian ruang pori dalam tanah. Pemberian biochar pada tanah tergolong sangat baik dalam meningkatkan konsentrasi karbon, kesuburan dan produktivitas tanah. Penambahan biochar ke dalam tanah dapat memperbaiki sifat fisika tanah yaitu struktur, porositas dan konsistensi tanah, distribusi ruang pori dan kerapatan (Paul, 2007).

Pengaplikasian biochar ke dalam tanah mampu memperbaiki kualitas tanah sehingga dapat meningkatkan produksi tanaman (Nurida dan Rachman, 2012). Dari hasil penelitian didapatkan bahwa pemberian biochar ke tanah dapat meningkatkan produktivitas tanaman sebesar 20 - 22\% dengan pemberian biochar sebesar 4 - 8 ton ha ${ }^{-1}$, hasil produktivitas tersebut tergantung pada tanaman yang dibudidayakan (Gani, 2009). Dalam penelitian Azis et al. (2015), hasil tanaman kedelai dapat meningkatkan sebanyak 0,93 ton $\mathrm{ha}^{-1}$ akibat pemberian biochar dengan dosis 10 ton ha ${ }^{-1}$.

Kedelai merupakan tanaman tahunan yang dapat tumbuh diberbagai jenis tanah terutama tanah yang berdrainase baik dan memiliki air yang memadai selama proses pertumbuhannya (Suprapto, 2004). Komoditas tanaman pangan terbesar ketiga setelah padi dan jagung adalah kedelai. Tingginya tingkat konsumsi kedelai oleh masyarakat Indonesia berbanding terbalik dengan kapasitas produksi kedelai Indonesia. Ketidakstabilan produksi kedelai di Indonesia disebabkan oleh penggunaan pupuk kimia yang terus menerus sehingga menyebabkan penurunan kesuburan tanah (Malian dan Husni, 2004). Oleh karena itu dibutuhkannya alternatif lain untuk memperbaiki kualitas tanah sehingga dapat meningkatkan produktivitas tanaman, salah satunya biochar. 


\section{METODE PENELITIAN}

Penelitian ini dilaksanakan di kebun percobaan ACIAR Fakultas Pertanian Universitas Syiah Kuala, analisis sampel tanah dilakukan di Laboratorium Fisika Tanah dan analisis kadar hara tanaman dilakukan di Laboratorium Penelitian Tanah dan Tanaman Fakultas Pertanian Universitas Syiah kuala. Penelitian lapangan dan Laboratorium dilaksanakan sejak bulan Juli hingga November 2020. Analisis tanah awal dilakukan pada bulan September 2019. Alat yang digunakan dalam penelitian adalah cangkul, ring sampel, meteran, gembor, dan alat-alat di Laboratorium Fisika Tanah serta Laboratorium Tanah dan Tanaman Fakultas Pertanian Universitas Syiah Kuala. Bahan yang digunakan dalam penelitian ini adalah sampel tanah yang telah ditanami tanaman jagung dan tanaman kedelai, benih kedelai varietas Anjasmoro, legin, pupuk dasar (Urea, SP-36, dan $\mathrm{KCl}$ ), furadan, serta bahan-bahan yang diperlukan untuk analisis di Laboratorium Fisika Tanah serta Laboratorium Tanah dan Tanaman Fakultas Pertanian Universitas Syiah Kuala.

Metode yang digunakan dalam penelitian ini yaitu rancangan acak kelompok (RAK) non faktorial. Percobaan ini dilakukan dengan empat perlakuan ukuran partikel biochar dan tiga kali ulangan sehingga dihasilkan 12 satuan plot percobaan dengan dosis biochar 15 ton $\mathrm{ha}^{-1}$ atau setara dengan $9 \mathrm{~kg}$ plot $^{-1}$. $\mathrm{P}_{0}$ : Kontrol, $\mathrm{P}_{1}$ : Biochar berukuran $5.00-2.00 \mathrm{~mm}, \mathrm{P}_{2}$ : Biochar berukuran 2.00 - $1.00 \mathrm{~mm}, \mathrm{P}_{3}$ : Biochar berukuran 1.00 - $0.5 \mathrm{~mm}$. Selanjutnya untuk mengetahui pengaruh dari pemberian ukuran partikel biochar bambu terhadap sifat fisika tanah, kadar hara tanaman, pertumbuhan dan produksi tanaman kedelai dilakukan analisis ragam (uji F) dan apabila terdapat perbedaan yang signifikan maka dilakukan uji lanjut Beda Nyata Jujur (BNJ) pada taraf 5\% dan $1 \%$.

\section{Parameter Pengamatan}

Parameter sifat fisika tanah dan kadar hara tanaman kedelai yang diamati disajikan pada Tabel 1 dan Tabel 2

Tabel 1. Parameter Sifat Fisika dan Metode Analisis

\begin{tabular}{clll}
\hline No. & \multicolumn{1}{c}{ Parameter } & Satuan & \multicolumn{1}{c}{ Metode } \\
\hline 1. & Berat Volume Tanah & $\mathrm{g} \mathrm{cm}^{-3}$ & Core Method \\
2. & Porositas & $\%$ & Penjenuhan Total \\
3. & Permeabilitas & $\mathrm{cm} \mathrm{jam}^{-1}$ & Constan Head \\
4. & Kapasitas Menyimpan Air & $\%$ & Gravimetrik \\
5. & Daya Hantar Listrik & $\mathrm{mS} \mathrm{cm}^{-1}$ & Konduktivimeter \\
6. & $\mathrm{pH}\left(\mathrm{H}_{2} \mathrm{O}\right)$ & - & Elektrometrik \\
\hline
\end{tabular}

Tabel 2. Parameter Kadar Hara Tanaman dan Metode Analisis

\begin{tabular}{clll}
\hline No. & Parameter & Satuan & \multicolumn{1}{c}{ Metode } \\
\hline 1. & N-total & $\%$ & Kjehdal \\
2. & P-total & $\%$ & Ekstrak 1 N NH $4 \mathrm{OAC} \mathrm{pH} \mathrm{7}$ \\
3. & K-total & $\%$ & Ekstrak 1 N NH $4 \mathrm{OAC} \mathrm{pH} \mathrm{7}$ \\
\hline
\end{tabular}

Parameter Produksi Tanama meliputi:

1. Polong berisi,

2. Polong hampa

3. Total polong 

4. Berat biji kering
5. Berat 100 biji
6. Produksi tanaman kedelai ton $\mathrm{ha}^{-1}$

\section{HASIL DAN PEMBAHASAN}

\section{Sifat Fisika Tanah}

Hasil analisis sifat fisika tanah musim tanam pertama dan musim tanam kedua akibat pemberian biochar bambu dengan berbagai ukuran dapat dilihat pada Tabel 3.

Tabel 3. Hasil Analisis Sifat Fisika Tanah akibat Pemberian Biochar Bambu dengan berbagai Ukuran

\begin{tabular}{lccc}
\hline Sifat Fisika Tanah & Perlakuan & Musim Tanam Pertama & Musim Tanam Kedua \\
\hline & $\mathrm{P}_{0}$ & 1,44 & 1,35 \\
Berat Volume Tanah & $\mathrm{P}_{1}$ & 1,43 & 1,36 \\
$\left(\mathrm{~g} \mathrm{~cm}^{-3}\right)$ & $\mathrm{P}_{2}$ & 1,42 & 1,35 \\
& $\mathrm{P}_{3}$ & 1,43 & 1,34 \\
\hline \multirow{3}{*}{ Porositas } & $\mathrm{P}_{0}$ & 45,89 & 50,93 \\
$(\%)$ & $\mathrm{P}_{1}$ & 46,14 & 47,24 \\
& $\mathrm{P}_{2}$ & 46,19 & 49,08 \\
& $\mathrm{P}_{3}$ & 45,89 & 49,46 \\
\hline \multirow{2}{*}{ Permeabilitas } & $\mathrm{P}_{0}$ & 3,42 & 3,79 \\
$\left(\mathrm{~cm} \mathrm{jam}^{-1}\right)$ & $\mathrm{P}_{1}$ & 2,63 & 4,08 \\
& $\mathrm{P}_{2}$ & 3,38 & 3,67 \\
\hline Kapasitas & $\mathrm{P}_{3}$ & 4,33 & 5,05 \\
Menyimpan Air & $\mathrm{P}_{2}$ & 18,14 & 22,76 \\
$($ WHC) & $\mathrm{P}_{1}$ & 17,86 & 24,76 \\
$(\%)$ & $\mathrm{P}_{2}$ & 18,33 & 24,97 \\
\hline Daya Hantar Listrik & $\mathrm{P}_{3}$ & 17,61 & 26,60 \\
$($ DHL) & $\mathrm{P}_{0}$ & 0,27 & 0,18 \\
$\left(\mathrm{mS} \mathrm{cm}{ }^{-1}\right)$ & $\mathrm{P}_{1}$ & 0,30 & 0,18 \\
& $\mathrm{P}_{2}$ & 0,33 & 0,21 \\
& $\mathrm{P}_{3}$ & 0,34 & 0,26 \\
\hline \multirow{2}{*}{ pH Tanah $\left(\mathrm{H}_{2} \mathrm{O}\right)$} & $\mathrm{P}_{0}$ & 8,30 & 8,10 \\
& $\mathrm{P}_{1}$ & 8,53 & 8,17 \\
& $\mathrm{P}_{2}$ & 8,53 & 8,10 \\
& $\mathrm{P}_{3}$ & 8,33 & 8,13 \\
\hline
\end{tabular}

Berdasarkan analisis sidik ragam didapatkan bahwa sifat fisika tanah pada musim tanam pertama dan musim tanam kedua tidak berpengaruh nyata terhadap pemberian biochar bambu dengan berbagai ukuran. Nilai sifat fisika tanah musim tanam pertama dan kedua pada Tabel 3 jika dilihat dari data statistik mengalami perbedaan, hal ini diduga akibat pemberian biochar bambu. Nilai berat volume tanah mengalami penurunan pada musim tanam kedua dan nilai porositas mengalami peningkatan pada musim tanam kedua. Meningkatnya nilai porositas sejalan dengan menurunnya berat volume tanah, sehingga banyaknya suatu massa tanah dalam suatu volume tanah menentukan banyak ruang pori di dalam tanah tersebut. Hal ini sejalan dengan Masulili et al. (2010) yang menyatakan bahwa pemberian biochar pada tanah menyebabkan pengaruh yang signifikan terhadap penurunan berat volume tanah dan meningkatkan porositas tanah. Semakin rendah porositas tanah maka semakin tinggi nilai berat volume tanah dan sebaliknya.

Di dalam tanah permeabilitas erat kaitannya dengan porositas tanah. Hal ini didukung oleh pendapat Mauli (2008), yaitu permeabilitas sangat erat kaitannya dengan porositas tanah, semakin besar porositas tanah maka semakin besar permeabilitas tanah. Nilai kapasitas menyimpan air (WHC) pada musim tanam kedua mengalami peningkatan dibandingkan 
dengan musim tanam pertama. Hal ini diduga karena pemberian biochar bambu dengan berbagai ukuran pada musim tanam pertama. Kapasitas menyimpan air erat kaitannya dengan berat volume tanah dan porositas tanah, yang mana berat volume tanah dan porositas dapat mempengaruhi kapasitas tanah dalam menahan air (WHC) sehingga air dapat mengisi ruang kosong diantara partikel tanah (pori-pori tanah) (Hardiansyah, 2012).

Nilai daya hantar listrik lebih tinggi pada musim tanam pertama dibandingkan dengan nilai daya hantar listrik pada musim tanam kedua. Hal ini diduga karena kemampuan mengalirkan arus pada tanah ini tergolong kecil dan kadar garam yang terkandung tegolong kecil. Kandungan ion dapat dipertukarkan yang terdapat pada permukaan partikel padat tanah dan eksistensi kandungan garam bebas yang terdapat pada kadar air tanah dapat menyebabkan terjadinya daya hantar listrik tanah (Rhoades et al., 1999). Penambahan biochar ke dalam tanah dapat meningkatkan atau menurunkan $\mathrm{pH}$ tanah, tergantung pada kandungan biochar serta nilai pH pada biochar (Ansori, 2000).

\section{Kadar Hara Tanaman Kedelai}

Hasil analisis menunjukkan bahwa pemberian biochar bambu dengan berbagai ukuran tidak berpengaruh nyata terhadap parameter kadar hara P-total dan K-total tanaman kedelai tetapi berpengaruh nyata terhadap parameter kadar hara $\mathrm{N}$-total pada taraf $1 \%$. Nilai kadar hara tanaman akibat pemberian biochar bambu dengan berbagai ukuran dapat dilihat pada Tabel 4.

Tabel 4. Kadar Hara Tanaman akibat Pemberian Biochar Bambu dengan berbagai Ukuran

\begin{tabular}{cccc}
\hline Perlakuan & $\begin{array}{c}\text { N-Total } \\
(\%)\end{array}$ & $\begin{array}{c}\text { P-Total } \\
(\%)\end{array}$ & $\begin{array}{c}\text { K-Total } \\
(\%)\end{array}$ \\
\hline $\mathrm{P}_{0}$ & $3,21 \mathrm{~b}$ & 0,60 & 1,54 \\
$\mathrm{P}_{1}$ & $3,06 \mathrm{ab}$ & 0,65 & 1,64 \\
$\mathrm{P}_{2}$ & $2,93 \mathrm{a}$ & 0,77 & 1,37 \\
$\mathrm{P}_{3}$ & $3,45 \mathrm{c}$ & 0,66 & 1,38 \\
\hline $\mathrm{BNJ}$ & 0,23 & - & - \\
\hline
\end{tabular}

Berdasarkan analisis sidik ragam didapatkan bahwa pemberian biochar bambu dengan berbagai ukuran berpengaruh sangat nyata terhadap kadar hara $\mathrm{N}$, perlakuan $\mathrm{P}_{3}$ berpengaruh nyata terhadap perlakuan $\mathrm{P}_{0}, \mathrm{P}_{1}$ dan $\mathrm{P}_{2}$, akan tetapi perlakuan $\mathrm{P}_{0}, \mathrm{P}_{1}$ dan $\mathrm{P}_{2}$ tidak saling berbeda nyata. Hal ini diduga biochar dapat meningkatkan ketersediaan hara $\mathrm{N}$ dalam tanah dengan mengikat hara $\mathrm{N}$ sehingga dapat diserap oleh tanaman. Hal ini sesuai dengan pendapat Sampurno et al. (2016), yang menyatakan bahwa penambahan biochar ke dalam tanah dapat meningkatkan $\mathrm{N}$-total sehingga hasil produksi menjadi meningkat.

\section{Produksi Tanaman Kedelai}

Hasil analisis sidik ragam menunjukkan bahwa pemberian biochar bambu dengan berbagai ukuran berpengaruh sangat nyata terhadap parameter bobot 100 biji tetapi tidak berpengaruh nyata terhadap parameter jumlah polong berisi, jumlah polong hampa, total polong, berat biji kering, dan produksi tanaman kedelai. Nilai produksi tanaman kedelai akibat pemberian biochar bambu dengan berbagai ukuran dapat dilihat pada Tabel 5 . 
Tabel 5. Nilai Rata-rata Parameter Produksi Tanaman Kedelai akibat Pemberian Biochar Bambu dengan Berbagai Ukuran

\begin{tabular}{ccccccc}
\hline \multirow{2}{*}{ Perlakuan } & $\begin{array}{c}\text { Jumlah } \\
\text { Polong } \\
\text { Berisi } \\
\text { (Polong) }\end{array}$ & $\begin{array}{c}\text { Jumlah } \\
\text { Polong } \\
\text { Hampa } \\
\text { (Polong) }\end{array}$ & $\begin{array}{c}\text { Total } \\
\text { Polong } \\
\text { (Polong) }\end{array}$ & $\begin{array}{c}\text { Berat Biji } \\
\text { Kering } \\
(\mathrm{g})\end{array}$ & $\begin{array}{c}\text { Bobot 100 } \\
\text { Biji } \\
(\mathrm{g})\end{array}$ & $\begin{array}{c}\text { Produksi } \\
\left(\text { ton }^{-1}\right)\end{array}$ \\
\hline $\mathrm{P}_{0}$ & 30,36 & 6,80 & 35,87 & 9,80 & $17,20 \mathrm{ab}$ & 1,09 \\
$\mathrm{P}_{1}$ & 33,86 & 5,00 & 37,57 & 11,50 & $19,00 \mathrm{~b}$ & 1,28 \\
$\mathrm{P}_{2}$ & 32,70 & 3,45 & 35,59 & 10,00 & $17,60 \mathrm{ab}$ & 0,96 \\
$\mathrm{P}_{3}$ & 42,10 & 8,43 & 49,90 & 13,10 & $15,40 \mathrm{a}$ & 1,31 \\
\hline BNJ & - & - & - & - & 2,85 & - \\
\hline
\end{tabular}

Pemberian biochar dengan berbagai ukuran berpengaruh sangat nyata terhadap bobot 100 biji tanaman kedelai. Perlakuan $\mathrm{P}_{1}$ berpengaruh nyata dengan perlakuan $\mathrm{P}_{3}$ akan tetapi tidak saling berpengaruh nyata terhadap perlakuan $\mathrm{P}_{0}$ dan $\mathrm{P}_{2}$. Hal ini diduga faktor genetik lebih dominan dalam mempengaruhi bobot 100 biji tanaman kedelai dari pada residu biochar. Hal ini sejalan dengan pendapat Soeprapto (2002) yang menegaskan bahwa besar atau beratnya biji tanaman kedelai sangat bervariasi tergantung dari faktor genetik suatu varietas. bobot 100 biji paling tinggi terdapat pada varietas Burangrang (17,67 g), varietas Dering I $(12,67 \mathrm{~g})$, varietas Anjasmoro (12,33 g), varietas Demas I (11,0 g) dan bobot 100 biji varietas Dering I yang ditanam secara tugal (11,67 g) (Hipi et al., 2015).

Jumlah polong berisi, jumlah polong hampa, total polong, berat biji kering, bobot 100 biji dan produksi tertinggi terdapat pada perlakuan $\mathrm{P}_{3}$ dengan nilai 42,10, 8,43, $49,90,13,10,15,40$ dan 1,31 ton $\mathrm{ha}^{-1}, \mathrm{P}_{3}$ merupakan pemberian biochar bambu berukuran 1.00 - $0.5 \mathrm{~mm}$. Pemberian biochar dapat memperbaiki sifat fisika, biologi dan kimia tanah sehingga mempengaruhi pertumbuhan dan perkembangan tanaman termasuk pembentukan polong yang lebih banyak (Nisa, 2010). Pemberian biochar dapat menyebabkan tanah menjadi lebih porous dan semakin besar kemungkinan terjadinya penyerapan hara tersedia dan hara anorganik yang berpengaruh terhadap proses pembentukan polong tanaman kedelai. Bobot biji tiap tanaman sangat erat kaitannya dengan persentase polong per tanaman, hal ini terlihat dari bobot biji tiap tanaman, semakin tinggi persentase polong berisi maka semakin tinggi bobot biji tiap tanaman (Nurlisan et al., 2014).

Aplikasi biochar dapat menunjukkan efektivitasnya dilapangan tergantung cara pemberian dan jenis tanaman yang diusahakan. Pengaruh biochar terhadap produktivitas tanaman tergantung pada jumlah penambahannya ke dalam tanah (Lehmann, 2007). Dalam penelitian Azis et al. (2015), penggunaan biochar dengan dosis 10 ton $\mathrm{ha}^{-1}$ dapat meningkatkan hasil produksi kedelai sebesar 0,93 ton $^{-1} a^{-1}$.

\section{KESIMPULAN}

Pemberian biochar bambu dengan berbagai ukuran tidak berpengaruh nyata terhadap sifat fisika tanah setelah musim tanam pertama dan akhir musim tanam kedua. Parameter yang telah diamati yaitu berat volume tanah, porositas, permeabilitas, kapasitas menyimpan air (WHC), daya hantar listrik (EC) dan $\mathrm{pH}\left(\mathrm{H}_{2} \mathrm{O}\right)$ tanah. Pemberian biochar bambu dengan berbagai ukuran berpengaruh sangat nyata pada taraf $1 \%$ terhadap kadar hara $\mathrm{N}$-total tetapi kadar hara P-total dan K-total tanaman kedelai tidak berpengaruh nyata. Pemberian biochar bambu dengan berbagai ukuran berpengaruh sangat nyata pada taraf $1 \%$ hanya pada berat 100 biji sedangkan parameter produksi yang lain seperti polong berisi, polong hampa, total polong dan berat biji kering tidak berpengaruh nyata. Produksi tertinggi terdapat pada perlakuan $\mathrm{P}_{3}$ 
dengan nilai 1,31 ton $\mathrm{ha}^{-1}$. Biochar bambu berukuran $1.00-0.5 \mathrm{~mm}\left(\mathrm{P}_{3}\right)$ secara keseluruhan menunjukkan hasil baik dibandingkan dengan ukuran biochar bambu lainnya.

\section{DAFTAR PUSTAKA}

Ansori. 2000. Pengaruh bahan organik pada sifat biologi tanah. http://www.google.com/ pengaruh+bahan+organik+terhadap+phtanah. Diakses tanggal: 6 Desember 2020.

Aziz, A., B.A. Bakar dan Chairunas. 2015. Pengaruh penggunaan biochar terhadap efisiensi pemupukan kedelai di lahan sawah Kabupaten Aceh Timur. Prosiding Seminar Hasil Penelitian Tanaman Aneka Kacang dan Umbi, Aceh.

Gani, A. 2009. Potensi arang hayati biochar sebagai komponen perbaikan produktivitas lahan pertanian. Iptek Tanaman Pangan. 4(1): 33-48.

Hardiansyah, G. 2012. Analisis pertumbuhan tanaman meranti pada sistem tebang pilih tanam jalur (TPTJ). Vokasi. 8(3): 165-171.

Haryadi, A. 2016. Pengaruh residu biochar terhadap pertumbuhan dan serapan $\mathrm{N}$ dan $\mathrm{K}$ tanaman kedelai (Glycine max L.) pada topsoil dan subsoil tanah Ultisol. Skipsi. Jurusan Agroteknologi Fakultas Pertanian Universitas Lampung, Lampung.

Hipi, A., N. Herawati., Y. Sulistyawati dan Sudarto. 2015. Karakteristik Agronomis dan Produktivitas Tujuh Varietas Unggul Kedelai Di Lahan Kering Beriklim Kering. Balai Pengkajian Teknologi Pertanian NTB, Nusa Tenggara Barat.

Hua, L., W. Wu., Y. Liu., M.B. Mcbride dan Y. Chen. 2009. Reduction of Nitrogen loss and $\mathrm{Cu}$ and $\mathrm{Zn}$ mobility during sludge composting with the bamboo charcoal amendment. Environment science and pollution research. 16(1): 1-9.

Lee, J.F., B. Hawkins., X. Li dan D.M. Day. 2013. Biochar Fertilizer for Soil Amendment and Carbon Sequestration. Springer, New York.

Lehmann, J. 2007. Bioenergy in the black. Frontiers in Ecology and the Environment. 5(7): 381-387.

Malian, A dan Husni. 2004. Kebijakan Perdagangan Internasional Komoditas Pertanian Di Indonesia. Pusat Analisis Sosial Ekonomi dan Kebijakan Pertanian, Bogor.

Masulili, A., W.H. Utomo dan Syechfani. 2010. The characteristics of rice husk biochar and its influence on the properties of acid sulfate soils and rice grown in West Kalimantan Indonesia. Journal of Agricultural Science. 2(1): 39-47.

Mauli, R.L. 2008. Kajian Sifat Fisika dan Kimia Tanah Akibat Sistem Rotasi Penggunaan Lahan Tembakau Deli. Universitas Sumatera Utara, Medan.

Nisa, K. 2010. Pengaruh pemupukan NPK dan biochar terhadap sifat kimia tanah, serapan hara dan hasil tanaman padi sawah. Thesis. Universitas Syiah Kuala, Banda Aceh.

Nurhayati, T. 2000. Percobaan Pembuatan Arang Aktif dari Bambu. Penelitian Bambu Indonesia, Jakarta.

Nurida, N.L dan A. Rachman. 2012. Alternatif Pemulihan Lahan Kering Masam Terdegradasi dengan Formula Pembenah Tanah Biochar Di Typic Hapludults Lampung. Balai Penelitian Tanah, Lampung.

Nurlisan, A. Rasyad dan S. Yoseva. 2014. Pengaruh pemberian pupuk organik terhadap pertumbuhan dan hasil tanaman kedelai (Glycine max (L.) Merril). Jurnal Online Mahasiswa. 1(1): 1-9.

Paul, E.A. 2007. Soil Microbiology, Ecology and Biochemistry. Elsevier, Amsterdam.

Rhoades, J.D., F. Canduvi dan S. Lesch. 1999. Soil Salinity Assement: Method and Interpretation of Electrical Conductivity Measurement. FAO United Nations, USA. 
Santi, L.P dan D.H. Goenadi. 2010. Pemanfaatan biochar sebagai pembawa mikroba untuk pemantapan agregat tanah Ultisol dari taman Bogo-Lampung. Menara Perkebunan. 78(2): 55-63.

Shenbagavalli, S dan Mahimairaja. 2012. Characterization and effect of biochar on nitrogen and carbon dynamics in soil. International Journal of Advanced Biological Research. 2(2): 249-255.

Soeprapto, H.S. 2002. Bertanam Kedelai. Penebar Swadaya, Jakarta.

Tang, J., W. Zhu., R. Kookana dan A. Katayama. 2013. Characteristics of biochar and its application in remediation of contaminated soil. Journal of Bioscience and Bioengineering. 116(6): 653-659. 